\title{
The policy agora: how power inequalities affect the interaction between researchers and policy makers
}

\author{
Chris Brown, Institute of Education, London, christopher.brown@mac.com
}

Introduction

Notions of power and what it means to be powerful have been conceptualized, explored and expounded since the time of Aristotle. To date, however, there have only been few theoretical or empirical examinations of policy development which have directly considered how power affects the use of evidence by policy-makers (existing examples include Ball, 2008 and 2012). In order to augment extant theory and empirical analysis in this area, the effects of power inequalities between researchers and policy makers were explored in Brown (2011), which sought to answer two broader questions: What factors affect the adoption of research within educational policy making?; and: How might a better understanding of these factors improve research adoption and aid the development of policy? Data from the project have been used within this paper to explore four key areas. Firstly, I outline current conceptualizations of how power operates in society. Secondly, I use the notion of the policy 'agora' to spotlight the implications of power inequalities for the use of evidence in the development of policy. Thirdly, I define what I consider as evidence 'misuse', before finally finishing with an analysis of why evidence misuse materializes and also how its enactment might be minimised.

\section{Methodology}

This paper builds on a research project undertaken between 2009 and 2011, that utilized a literature review and in-depth, semi-structured interviews (Brown, 2011). The aim of the literature review was to provide an overview of existing theory and an understanding of the type of empirical studies previously undertaken in this area. Literature was initially searched for in two ways: i) a search of four prominent databases (JSTOR; Academic Search Complete; Web of Knowledge; IngentaConnect) using search terms synonymous with that of 'evidenceinformed policy making' and 'knowledge adoption' (such terms included, for example, 'knowledge mobilisation', 'knowledge transfer' and 'knowledge brokering', and were taken from the definitive list provided on The University of Toronto's Research Supporting Practice 
in Education website) ${ }^{1}$; and ii) recommendations on seminal literature in these areas were also sought from (and provided by) colleagues, authors identified from the search above, and experts in the fields of evidence-informed policy making and knowledge utilisation. The references cited by the authors of these studies were then also reviewed. In total, 228 papers, studies, reports and books were reviewed over a one and a half year period: the depth and breadth of the literature reviewed designed to ensure that the analysis was fully grounded within current thinking regarding both research utilisation/knowledge mobilisation and evidence-informed policy making.

In addition, a total of, 24 semi-structured, in-depth interviews were held with educational researchers and policy-makers working in England. Those classed as policy-makers were either politicians (current or ex-Ministers) or Civil Servants in central government. Researcher respondents comprised those working for Universities or think tanks. ${ }^{2}$ Whilst a purposeful sample of 'critical cases', corresponding directly to the analytical requirements of the project were selected (Brown and Dowling, 1998), care was taken to include both advocates and those critical of current approaches to developing and embeding evidenceinformed policy (with potential respondents initially selected based on a combination of personal knowledge and in relation to articles or conference papers written or given in this area). Overall this approach provided a wide range of views and opinions from which to draw upon and assess. It also provided a rigorous critique of the analysis and its resultant conceptual/theoretical development.

The distribution of the final participants is presented below (note the number adds to more than the total interviewed as these groups are not mutually exclusive). Given the make-up of the respondents, the analysis should be regarding as primarily relating directly to the sphere of educational research and to educational policy making in the United Kingdom. In addition fieldwork was undertaken during 2010 and so reflects the end of the UK's last (New Labour) government and the election of the current (Conservative-Liberal Democrat) Coalition.

\section{Table 1: Distribution of interview participants}

\footnotetext{
${ }^{1}$ See: http://www.oise.utoronto.ca/rspe/KM_Products/Terminology/index.html

${ }^{2}$ Given the prominence of some of those interviewed, ethical consideration and approval was required regarding my duty of care in relation to the anonymity of respondents.
} 
Table 1: Distribution of interview participants

\begin{tabular}{|l|l|}
\hline Group/view point & Number \\
\hline Politicians based in England and Wales & 2 \\
\hline Civil servants based in England and Wales & 4 \\
\hline $\begin{array}{l}\text { Researchers considered from the literature, or self identified, as } \\
\text { favoured by politicians or civil servants }\end{array}$ & 9 \\
\hline $\begin{array}{l}\text { Researchers considered from the literature, or self identified, as } \\
\text { less favoured by politicians or civil servants }\end{array}$ & 6 \\
\hline $\begin{array}{l}\text { Academic researchers critical of the concept of evidence-informed } \\
\text { policy }\end{array}$ & 4 \\
\hline Academic researchers in favour of evidence-informed policy & 11 \\
\hline $\begin{array}{l}\text { Respondents belonging to think tanks, political advisors or those } \\
\text { operating at the higher levels of Davies' (2006) policy making } \\
\text { 'food chain' }\end{array}$ & 3 \\
\hline Total & 24 \\
\hline
\end{tabular}

Following the interviews, thematic analysis was employed to identify the key evidenceinformed or knowledge adoption-related behaviours that were or might be employed by researchers and policy-makers. Themes and codes were developed empirically through the breakdown of the data generated in the interviews. Empirical coding may be regarded synonymous with inductive analysis; that is, where data analysis precedes the development of theory. Theoretical development within the study began, however, with the literature review and was thus augmented rather than initiated during the data analysis stage. This approach corresponds to Mason's (2002: 180) definition of 'abductive' analysis where "theory, data generation and data analysis are developed simultaneously in a dialectical process". Mason's (2002) posited approach thus accounts for the way in which the research process moved back and forth between analysis and the development of theory, detailing themes and constructing codes relating to knowledge adoption from both the interview data, and the literature review.

\section{A definition of 'evidence'}

From engaging with the literature, I argue that there is a conspicuous lack of clarity between definitions of knowledge and the notions of research or evidence (Brown, 2011). This 
reflects suggestions by Nutley et al. (2007: 25) who argue that: "definitions of... research, evidence and knowledge invariably invoke implied accounts of at least one other". As a result, the terms 'research' (or, more specifically, 'research findings'), 'evidence' and knowledge are taken here to encompass the spectrum of what it is that educational policymakers might consider in the creation of 'evidence' informed-policy (and are used interchangeably throughout). Correspondingly, I take my collective definition for these terms from Brown (2011: 269), that is as: "data that has been gathered via a process of research, which has been interpreted and which subsequently has or could be used to address a particular policy issue".

\section{Power and policy development}

I use this first section of the paper to outline contemporary conceptualizations of how power operates in society. I start with the work of Jürgen Habermas, the most renowned member of the 'Frankfurt School', whose notion of 'communicative action' forms the basis for his model of 'ideal' democratic process. I then contrast Habermas's work with Michel Foucault's 'genealogical approach': i.e. one which posits that we should dig beneath our commonly held views and assumptions to discover where power truly manifests itself. Habermas and Foucault are not the only exponents of power theories, but their notions of power perhaps best suit an examination of evidence use by UK or 'westernized' government. For instance, other conceptions of power, such as that posited by political and social theorist Steven Lukes (2005), tend to regard it in terms of a 'force' which acts as a tangible constraint on human activity (sometimes even resulting in physically constraining or violent outcomes). Instead, I argue that rather than being something direct and observable, power, in relation to policy-making, exists in the form of strategies that often indirectly guide actions and though their continued reproduction come to form norms. Unlike with more direct conceptions of power, which must have immediately observable cause and effect, the originator of these strategies and so a specific wielder of power cannot always be determined. In addition people may also willingly engage with or positively react to these strategies as part of their decision-making processes.

\section{Jürgen Habermas}


The work of critical theorist Jürgen Habermas is principally concerned with rationality, in particular, how rational decision-making can be facilitated in modern democratic societies. Habermas's thesis is dependent on his theory of 'communicative action'; action oriented towards reaching agreement, which, Habermas contends, is the fundamental type of social action. In turn, communicative action depends on a further premise; the notion that discourse is used by people as an everyday process of making claims to validity. These two premises enable Habermas to conceive of civic life as comprising networks of relationships that display two principle characteristics: firstly they are cooperative - this is because the success of any interaction depends upon the interdependent activity of both narrators and audiences (respectively as producers and receivers of the communicative act); secondly that discourse must have a rational dimension: a narrator will seek to provide reasons for the validity of their communicative act, knowing that their counterpart (the audience) may either accept it or counter it with a better argument. Habermas's twin premises of mutual agreement and discursive validity also allow him to set out a vision which positions valid and rational arguments as the basis for all major decisions. In other words, in a Habermassianbased society, policy development and other major acts of government are ultimately determined by what Habermas describes as 'the force of the better argument', which represents a "cooperative search for truth" (1990: 198: my emphasis). Habermas thus conceives of power as something that is constantly ameliorated by rationality: power is only afforded to individuals or institutions in instances where they can successfully argue their case. The notion of the better argument, meanwhile, is 'policed' by rules established by Habermas to uphold the validity of arguments (Habermas' five 'tenets' of discourse ethics: see Habermas and Cooke, 1999).

The Habermassian approach would appear to reflect the rhetoric of evidence-informed policy making as espoused by both researcher and policy-maker advocates. For example, the consequence of Habermas's analysis emphasizes policy development based on: widespread public participation; the extensive sharing of information that might inform decisions; consensus reached through public dialogue rather than the exercise of bureaucratic power; a reduction of the privilege afforded to policy-makers based solely on their position; and the morphing of the role of policy-maker from policy technician to that of the reflective practitioner. (e.g. see: Argyris and Schön, 1974; Schön, 1983; Innes, 1995; Lauria and Soll 1996). As such, Habermas argues that the legitimacy of policies cannot simply be viewed in terms of whether policy-makers have acted intra vires, but also on the nature and the 
quality of the deliberation that preceded this action. Evidence therefore has a key role to play in shaping decisions via actions such as informing citizens with regards to particular issues, or providing policy-makers with a myriad of perspectives with which to inform their decisions. Researchers in a Habermassian system are thus afforded pivotal positions as both gatekeepers to and the interpreters of, knowledge.

Habermas's model democratic process can be critiqued, however, precisely because it represents an ideal; i.e. it represents a type of government that should be aspired to and Habermas does little to address either government in its current state or how power materialises in actuality (Flyvbjerg, 2001). Instead, Habermas immerses himself within a perspective of structures: he principally concerns himself with establishing what might be required in order for rational argument to flourish, as well as with identifying procedures to establish democratic consensus based on the outcomes of argument. Habermas's solution is to resort to 'the legal institutionalization of those forms of communication necessary for democratic will formation' (undated: 15). This focus on how democratic processes should work, rather than how they do currently, leads Flyvbjerg to contend that 'the basic weakness of Habermas's project is its lack of agreement between idea and reality, between intentions and their implementation' (1998:215). But Habermas's work is perhaps also open to an even more basic critique: whilst the Habermasian system is centred on consensus building as the fundamental type of social action, many other social commentators and philosophers believe that the exact opposite is in fact true (e.g. see Brown 2013). Such critique implies that, instead, we should enquire as to how claims to validity are constructed, how politics and democracy operate and so what comprises the wider discursive milieu in which policy is formulated. In particular, to ask whether validity really is characterized by consensus seeking and the amelioration of power or whether it, and the process of communication which leads to it is, in itself, part and parcel of the exercise of power (Flyvbjerg, 1998).

\section{Michel Foucault}

A counter position to Habermas's democratic utopia is provided by Michel Foucault. Habermas's notion of power and its amelioration by legal and democratic frameworks, contrasts significantly with that of Foucault; who argues that his own analysis is only possible because it has 'abandon[ed] the juridical model...[that] makes the law the basic manifestation of power' (Foucault, 2004: 265). Whilst Habermas argues for a system 
governed by universally accepted and applicable democratic principles (i.e. which involve processes for establishing consensus around and the normative validity of, arguments), Foucault argues that such principles do not exist. Instead, Foucault suggests that the worldviews of social groups are contextually grounded (and so truth, 'perspectival and strategic': $2004,268)$. Such a position not only rules out Habermas's invocation of the general principle of 'the better argument'; since there is no neutral or a priori way in which this can be judged, it also negates the possibility of social groups or institutions operating in ways that might be considered 'value neutral' or in accordance with any universal truth. Subsequently, rather than concern himself with the construction of mechanisms which provide a blueprint for how utopian government might operate, Foucault's work is 'genealogical'; it describes the genesis of a given situation in order to illustrate how it was arrived at. This enables Foucault to demonstrate that what is often taken for granted has not always been so and that alternatives are possible. Foucault specifically describes the task of laying open norms and the identification of alternatives as: "criticiz[ing] the working of institutions which appear to be both neutral and independent; to criticize them in such a manner that the political violence which has always exercised itself obscurely through them will be unmasked, so that one can fight them." (Chomsky and Foucault, 1974:171). Genealogy in the policy context thus requires i) an examination of existing procedures in order to establish how policies are created, announced, interpreted and enacted; and ii) an unpicking of the taken for granted norms that current procedures produce and reproduce, in order that instances of power abuse might be uncovered.

\section{The exercise of power through discursive control}

When policy-makers exercise power they do not, in the UK context at least, employ direct coercion; they achieve their goals by dictating what constitutes 'normative' reality. In other words, whilst there may be a myriad of social realities, those in power are better placed to promote their perspectives as 'normal'. Foucault describes this notion as the 'will to knowledge'; the desire by social groups to advance their version of events. Key to the successful operation of the 'will to knowledge' is how knowledge might be disseminated: this affects how power is enforced or maintained and how it is undermined. Foucault suggests that this role is played by discourse (the language that is employed by people to construct versions of the social world). For instance, in terms of maintaining power, Foucault (1980) argues that each society has a 'regime of truth': discursive realities which are not only 
accepted as true, but which are also made to function as true (e.g. via affording status to those charged with pronouncing the truth). In such cases, the dissemination of discourse facilitates control over what those in power wish to promote as the truth: power is synonymous with the promotion of the 'true' knowledge of the status quo and the discourse that results is specifically designed to uphold the current, specific 'regime of truth'. Foucault (1978: 100-101) also notes, however, that: "discourses are not once and for all subservient to power... discourse can be both an instrument and an effect of power, but also a hindrance, a stumbling block, a point of resistance and a starting point for an opposing strategy". Discourses formed as part of the appropriation of knowledge can also be used, therefore, to seek to undermine existing power relations through the promotion of alternative 'truth regimes'. As such, Foucaultian analysis should be thought of as positioning discourses as sets of practices, with each serving to promote given ideologies, whilst also working to remove others from general circulation.

\section{The policy agora}

The analysis above opens the possibility that, rather than evidence use by policy-makers being dependent upon how well researchers have argued the case for its inclusion (the Habermasian approach); the topics of investigation, the methods researchers employ and the way in which evidence is communicated and/or married to policy issues, can perhaps all be affected by the discourse of government; i.e. by any given governments 'regime of truth'. Should this be true then a logical consequence is the suggestion that, if researchers wish to influence policy, they will need to ensure that their subject areas, approaches and narratives are compatible with the current dominant political philosophy and/or ideas that are currently privileged, or risk their work being excluded. Ideological and epistemological salience (both in terms of methodology and in terms of 'surface-level' concerns) are thus likely to be key drivers in determining which evidence policy-makers are likely to adopt.

By including in this analysis the notions of 'Mode 2' knowledge and the agora, however, I am able to formalize this analysis by establishing the notion of the 'policy agora' and to use it as a tool to illustrate how power operates with regards to evidence adoption: Gibbons et al. (1994) use the notion 'Mode 2' knowledge to represent research designed to be applied to specific problems right from its very inception. Gibbons et al. (1994) also posit that the validity of any knowledge produced will, in part, be determined by its users; this is referred 
to as the 'social robustness' of knowledge. In addition to the concept of 'Mode 2', Nowotny et al. (2003) and Gibbons (1999) also posit the idea of the 'agora' or the market place in which 'Mode 2' knowledge is both produced and 'traded' and suggest that within the agora sit numerous evidence 'experts', both academic and non-academic, with whom policymakers might engage to help find solutions to such problems.

As a resultant entity, the policy agora therefore represents the conjoin of the discursively established, ideological and epistemological preferences of policy-makers. The boundaries of the agora are thus defined by the range of ideas that are currently ideologically acceptable to policy-makers (as determined by the political priorities of the government of the day), juxtaposed against their epistemological concerns; for instance, whether a 'what works' type methodological approach has been employed and/or whether outputs have been designed to be 'policy-ready' (Brown, 2013). Within these boundaries of ideology and epistemology sits a space filled with the gamut of evidence that policy-makers are most likely to consider when developing policy (bearing in mind that they may not consider any evidence at all). Conversely, studies or ideas outside of the agora are more likely to be criticized and rejected: Ouimet et al. (2009) argue, for example, that if evidence is seen as politically irrelevant, then government departments are unlikely to spend significant resource attempting to engage with its findings. Censure or exclusion will also relate to the method employed by a research study and the type of evidence or suggestions such studies can provide to policy-makers. Likewise, within the agora will also sit numerous evidence providers, both academic and non-academic, with whom policy-makers might engage to help find solutions to such problems. The proposed nature of this 'wider' environment that determines which evidence is considered by policy-makers is illustrated diagrammatically in Figure 1, below.

Figure 1: The policy 'agora': the wider environment that determines which evidence is considered by policy-makers 


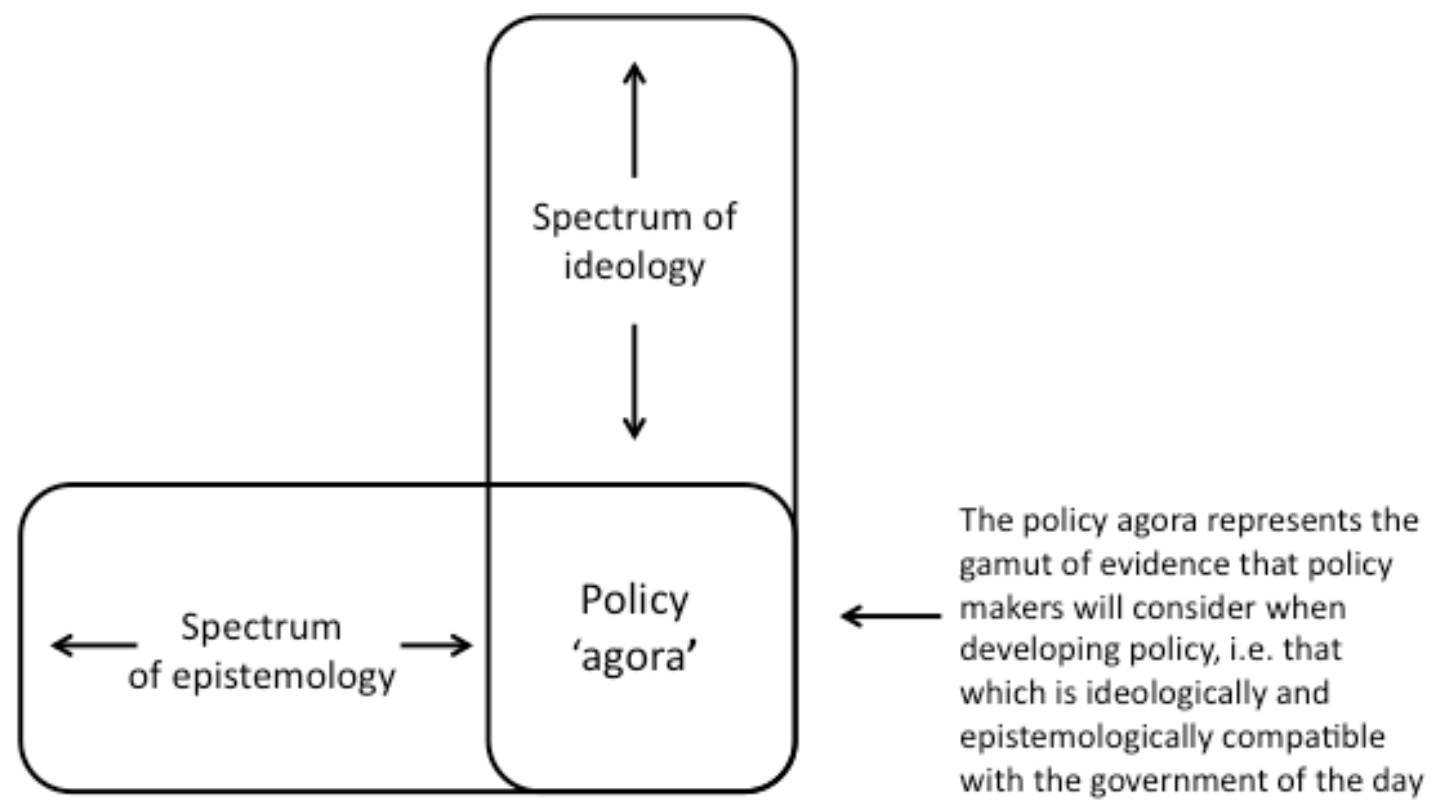

The operation of the agora

Based on the Foucaultian position, I argue that any given agora is established and will be held in position by the discourse employed by policy-makers. Whilst discursive dominance results in the normalization of a particular ideological or epistemological position, the boundaries or the policy agora are, however, capable of shifting and changing. One cause for such a shift will be through the political process; for example, the election of a new party (or coalition of parties) to government is almost certainly likely to lead to shifts or changes in the ideological or political paradigm as new policy commitments are introduced, based on new ideologies, evidence or ideas which had, hither to, existed outside of the agora (an example of this in relation to 'restorative justice' is given in Brown, 2011). Another way a policy agora might be shifted is via a growing weight of evidence for alternative viewpoints (see Brown, 2013). As a result, the nature of the ideological and epistemological paradigms that form the agora will also be a function of the existence of a wider corpus of knowledge or perspectives. Thus policy agoras will be broadly centred around dominant points of view (which form the mainstay of discursively promoted social realities) until these are shifted by the force of any consensus. I now set out to validate the concept of the agora and to suggest its nature, and 'shape' or areas of content, based on my abductive thematic analysis of interview data and current literature. I begin begin by looking at what interview data revealed regarding extant discourse on evidence use.

\section{Discourse in relation to evidence-use in educational policy development}


In my interviews with researchers and policy-makers, I witnessed and recorded a wealth of interesting discourse concerning the interaction between policy and evidence/policy-makers and researchers. At a macro level, this discourse seemed to be directed at three main areas: firstly, the level of sympathy evidence exhibits with regards to any currently dominant ideology (and the need for it to be so in order for it to be considered by policy-makers in the formation of policy): secondly, the need for evidence to conform to the epistemological concerns of policy-makers (typically the positivist in nature, see Brown, 2013); lastly, also ensuring that policy-makers' 'surface level' epistemological concerns were met: for instance, with regards to how evidence is presented and how findings are equated or married with policy issues.

For example, of those I interviewed all (both policy-makers and researchers) agreed, suggested or concurred that policy-makers require research inputs (i.e. topics of investigation) to be compatible with the residing political beliefs of the day and with the current direction of policy travel. In addition, that those responsible for policy will challenge or attempt to squash findings which are seen to run counter to given policy, or even to undermine the researchers providing them. One interviewee, a former government Minister, recounted the following example:

When we launched the... strategy [a respected academic researcher] came out and said that the... strategy was rubbish... [and that the researcher in question's own research undermined it]. And we'd not dreamt the... strategy out of thin air, we'd got [a second respected academic] to work on it and we felt that it was evidence based. And [the researcher providing the critique] made their announcement at a very difficult time for us politically. What we sensibly should have done is to say "look [the researcher providing the critique] is respected, will somebody look at it and let me know what they think". We didn't do that, what we did was try and undermine it and never spoke to [the researcher providing the critique] again.

One academic respondent described the following two situations where particular evidence was seen to run counter to the government of the day's beliefs and chosen policies and the subsequent reaction by policy-makers to this: 
I had a couple of run-ins with [a former Secretary of State]... one on [policy 1] where we wrote to [them] and described the evidence which was very solid against [the direction the government were taking with policy 1]. And... we had an absolutely vituperative letter back... and it was about four pages of really angry prose about us being old Labour. Actually I mean I'm not even a Labour supporter so I don't really claim to be old Labour. But it was quite extraordinary and obviously what could only kind of trip this is the knowledge that "actually the research might be right but I don't want to hear it and I'm going to rubbish anybody who says so".

And we also had a run in [concerning policy 2]... the research hit the headlines and it wasn't just our research, there was a number of other pieces of research showing that [policy 2] didn't have much effect on primary standards but obviously that was against the policy [direction]. So again you know I had kind of public dressing-down for that.

Those I interviewed also noted that methodological approaches must be considered 'robust', and sit within policy-makers' preferred epistemological paradigm. Civil service respondents, for instance, illustrated how studies viewed as incompatible with favoured epistemologies were handled in order that findings might be 'legitimately' dismissed or ignored. Preference was also regularly afforded to larger scale studies and meta-analyses:

Where the research is slight [it] wouldn't pass [our] quality control test... there's lots of little research [projects] in the system. We're big fans of systematic reviews.

\section{The discourse of marketization}

But researchers and evidence were also positioned by discourse that made reference to other 'ideals' that needed to be met, or to deficits that needed to be overcome. For example, my interviews with policy-makers and researchers spotlighted that a nascent trend in evidence use is the requirement by educational policy-makers for 'policy ready' research findings (see Brown 2011a; 2013). Other trends included the growing plethora of think tanks seeking to influence policy and the notion of 'socially robust' knowledge. I also argue in Brown (2011) that, in acting as choice laden consumers and in picking and choosing from the multitude of knowledge providers which now provide outputs that are 'policy ready', policy- 
makers have implicitly begun to 'marketize' the practice of research. As a process, marketization thus serves to introduce competition amongst evidence producers, with those organizations able to deliver the 'ideal' of 'policy-ready' findings, patronized and privileged over others.

During my interviews I was able to directly observe 'policy-ready' marketization in action, via the ways in which evidence was described and discussed. Trowler (2003) suggests that, as a phenomenon, marketization will involve the distillation and appropriation of discursive repertoires from business or marketing and from the language of consultancies or think tanks. For the policy-makers I interviewed, this initial permeation could be easily observed where, for instance, 'policy ready' related phrases or words such as: 'solutions', 'ideas', 'applications', 'implementation', 'impact', 'rendered fit for policy use' were all used when making reference to evidence. It also could be seen, however, in the discourses employed by those researchers who actively attempt to influence policy or produce 'policy ready' outputs (i.e. these researchers had incorporated and were acting in response to a discourse that had been originated by policy-makers). This is illustrated in the following example:

If you don't have that work in the middle to translate basic research into [policy applications] then it's very unlikely that research is going to influence anything...

The researchers not making this type of attempt, however, continued to employ more traditional academic phrases when describing what their research output might reveal about the empirical world. For example, by using terms such as: 'perspectives', 'critique', 'inform', 'complexity' and so on.

In theory at least, the process of marketization, as it relates to 'policy ready' findings, can be considered a positive phenomenon. This is because it serves to improve the output of researchers/universities by relating them to customer/public need (Shore and Wright, 1999). Outputs thus become spurred by what is required by society (via government) rather than by the whims or desires of individuals (i.e. outputs become more efficient uses of resource); as a result, the behaviours and actions of social actors become more efficient by being linked to these outputs. The discourse of 'policy-ready' can also operate to the detriment of researchers, however; with policy-makers expecting researchers to go beyond their traditional skill sets and spend more resource in producing specific types of evidence output 
but without either assisting this process or administering any reward for researchers doing so. For example, an examination of what was not said by policy-makers concerning 'policy ready' outputs also proved poignant: policy-makers made no suggestion, for instance, that 'policy ready' outputs should be born out of acts of partnership or that they (policy-makers) had a role in transforming research outputs. These omissions came despite the practical experience of policy that is required in order to produce 'policy ready' output; the proven effectiveness of partnership working in such situations (Sylva et al., 2007; Taggart et al., 2008); the obligations on policy-maker to explicitly specify their requirements from research so that they might be met by researchers (Rickinson et al., 2011), as well as the benefits to policy-makers themselves.

In addition, on the flipside of such discourse, policy-makers were also prone to promote a 'deficit' model of research(ers). For example, in my interviews, most policy-makers put forward comments in a similar vein to the following:

The way research is presented isn't helpful. Its presented, not interpreted or analysed or rendered fit for policy use... it doesn't say... what the applications are... Researchers often put their hands up and say, "that's not my job. My job is to report the world as it is, to hold a mirror up to nature". Well thanks, but we pay a six-figure sum for that privilege.

Researchers also set out the argument from their side of the fence:

there's been an awful lot of emphasis on improving communication from the research side... but there's been nothing like the same attention given to policymakers' receptiveness... so that they are willing to even engage with some of the research findings that come out... The emphasis is on research deficits, not on policy-makers themselves, how they might be stimulated to take into account the work that is out there.

As a consequence, as well as promoting 'policy ready' outputs, policy-makers would both castigate those who failed to provide such outputs whilst simultaneously giving primacy to the argument that researchers communicate evidence poorly. In other words to hold up notions of researcher 'deficit' in preference to other possibilities, for example, with regards 
to the extent of their [policy-makers'] ability to work in partnership with researchers, or any lack of capacity on the part of policy-makers to take on board academic evidence. The result of such additions to, or omissions from, the discursive lexicon employed by policy-makers is, therefore, that [some] academic researchers change their behaviour to meet that which is required; in other words, to act alone/without policy-maker assistance in the production of 'policy ready' (or 'what works') type outputs. Correspondingly, this supersedes the ability for researchers more generally to be able to engage with policy-makers in preferred, alternative ways. For example, through the process of policy 'enlightenment' (Weiss, 1980; 1982), where evidence serves to inform the medium to long term policy environment, rather than provide a direct steer on a particular issue (often, however, enlightenment may be the only realistic course available to researchers: for instance, where their research comprises complicated and complex messages that are not prone to an easy distillation in to simple recommendations).

There is also no guarantee that policy-makers will subsequently adopt any output that is produced (and so such efforts lead to only nominal benefit for the researcher themselves). An academic response to this 'push' isn't inevitable and this is confirmed by the responses of those interviewed. But, at the same time, the 'move away from traditional expertise' spotlights that, should researchers not wish to succumb to the forces of marketization, the value of their contribution may be systematically ignored or down-graded (in other words excluded from the agora) and alternative knowledge providers such as 'policy ready' researchers, think tanks or consultancies privileged instead.

\section{The implications of the policy agora for policy development}

Both politics and policy-making is fundamentally ideological in nature. As such, it may appear 'natural' that evidence which is incompatible with the views of the government of the day (i.e. that which sits outside of the agora) should be ignored. However, it was also suggested in my interview sessions that dogmatic adherence to a given set of ideological ideas will, by definition, lead to policy-makers failing to hear alternative views which might add value when attempting to solve a particular issue:

Well I think if you look at it across educational research you will find a range of different perspectives on many of the issues that policy-makers are concerned about 
and I think that educational research can be of great value precisely in providing those different perspectives.

In addition, the ideological paradigms for education favoured by both the previous New Labour and the current Conservative-Liberal Democrat government have within them common assumptions concerning how education should be structured and enacted in order for it to best serve the interests of the economy. These include, for example, the inclusion of specific subjects within the curriculum and the importance of continuously improving academic exam results (e.g. Ball, 2008, 2012; Eurydice Network, 2012 - this last source specifically looks at the efficacy of entrepreneurial education within schools). One academic researcher I interviewed, however, noted that this focus might not be the most effective approach in terms of meeting economic means:

Everything is [currently] judged in terms of grading examination papers and that itself is then taken to be an indicator of effectiveness in terms of economic [performance] in the global economy. And yet clearly a lot of research suggests that the sort of learning that is going on... is not the sort of learning that the economy [or the knowledge economy] actually requires.

Thus the narrowed and selective view of evidence implied by the existence of the agora is likely to mean that issues at the heart of the policy problem and, importantly, potential ways to address those issues, will not be fully considered. An effective insight, for example, may exist at point ' $A$ ', well outside the boundaries of what is being contemplated. Narrowing the 'epistemological infrastructure' (Atkinson, 2000) in this way is therefore likely to impact upon the efficacy of any proposed policy solution to meet its desired aims and move policy making away from the more effective, efficient and equitable outcomes it is suggested can accrue from considering an evidence base (Oakley, 2000; Oxman et al., 2009). Were policymakers to consider alternative perspectives, however, this might aid them in preventing instances of 'policy failure': as Hargreaves and Harris (2011) note, the organizations that successfully perform beyond expectations are those that can successfully marry pragmatism with ideology.

\section{Evidence misuse}


The notion of the policy agora and its function as an instrument of/tool to maintain power (i.e. through its role in normalizing particular ideological and epistemological positions) provides a platform from which I am able to develop the idea of evidence 'misuse'. It is clear from the analysis above that discursive power enables the powerful to successfully determine whether an idea will be privileged or not. That they might champion an idea, however, requires us to make certain assumptions about what motivates policy makers to act and in turn, this requires us to assume a certain level of rationality exists within the policy-system. Specifically, there are three assumptions that must hold here: i) that politicians are driven simultaneously both by ideology (and a desire to perpetuate this ideology through their re-election) and a desire to improve outcomes for at least certain subgroups of the population; ii) that sometimes ideology and tranches of evidence overlap (i.e. evidence is situated within the agora) and government can pursue evidence-informed policies should it wish. On other occasions, however, tranches of evidence will exist outside of what politicians might normally consider and so are most likely to be ignored and excluded by them; and iii) that the type of exclusion described in ii) may be overridden if Civil Servants (acting in an apolitical way: see Mountfield, 1999) are able to identify and then subsume the key messages from such research within the government's current agenda. In other words, to find ways in which pertinent or salient points may be incorporated to improve the efficacy of the government's preferred course of action, without necessarily adopting them as wholesale changes to policy direction.

As a consequence, I suggest that evidence misuse should be regarded as a situation in which any policy optimum is suppressed. Especially so, if this suppression is a function of political unacceptability, rather than where an action or direction is actually unachievable. In defining this situation, I therefore regard evidence misuse as a strategic discursive position, comprising instances of policy-makers successfully developing and implementing policy that ignores the perspectives suggested by a compelling weight of research evidence. Evidence misuse may be regarded as occurring in a number of situations. For example, when evidence is not used or selective evidence is used post-hoc, and any resultant decision flies in face of what a corpus of evidence existing within the agora recommends; or when evidence is only selected from within the agora but where pertinent alterative perspectives exists beyond its borders and could be used to enhance a policy-decision; Unlike in a Habermassian system, where this situation would be regarded as a result of government's failure to install systems to facilitate argument; or via Luke's (2005) conception of power, where researchers are 
directly coerced or forced to comply; my notion of evidence misuse is something which flourishes because the existence of discursive control on the part of policy-makers allows its enactment to be normalised and re-produced. In other words it exists and is allowed to exist because policy-makers can i) appeal to notions of 'common sense' to rubbish alternatives to their solutions (or the ideas held most dearly within their given constructed reality) and; ii) can drawdown on the deficit argument to argue that evidence is not timely in its production, has not been well communicated or that it fails to provide solutions.

Clearly, the occurrence of evidence misuse is co-dependent on the absence of justifiable cause: evidence misuse should not be considered to occur every time policy-makers fail to implement evidence as policy. Exceptions as to what might be considered as evidence misuse comprise, for example, where what evidence suggests is unaffordable or is simply unachievable, due to a lack of extant infrastructure. My definition does though include instances of where alternatives are dismissed simply due to ideological considerations. A quote by one former Secretary of State for Education I interviewed when exploring this topic nicely summarizes a hypothetical example of what I consider to be evidence misuse with regards to education policy development. This example refers to the consideration of grammar schools by an incumbent New Labour Government:

Even in opposition you tend to ignore the research that is counter to your political values... so if somebody comes to us and says "all the evidence says selection works" we are still not going to adopt it [selection], its just counter to what we do.

Thus if, in theory, a substantial tranche of evidence did indicate that 'selection worked', then Civil Servants could make attempts to ascertain the social drivers 'selection' activates/invokes. They could then seek to reproduce these drivers in a way more sympathetic to the ideological perspectives of the government of the day. The quote above, however, suggests that any such attempt would have been ruled out or findings dismissed by the Secretary of State at the time: as such I regard it as highlighting how the potential optimality of education policy might be supressed.

My definition of evidence misuse should not be seen as one which decries value-based politics, however: I believe that in a democratic society it is both unfeasible and undesirable to employ a fully technocratic approach to policy development. Politicians will quite rightly 
want to follow their convictions and/or what they feel they have been given a mandate to carry out by the electorate. They are also required to react in the face of media pressure to specific short-term crises. The voters who elected them will also have been driven by party allegiance (which is often ideological or conviction based) and/or personal experience and/or media spin. As such, it is not my suggestion that politicians must be guided by the force of the better argument (which in the Habermassian system is thus seen to result in the truth), but should, at least in part, be driven by a desire to make their policies as effective as possible by considering what a diverse range of perspectives have to offer.

Defining the concept of evidence misuse in this way should also not be confused with any adoption of a technical, rationalist perspective with regards to the role of research in policymaking. I argue (Brown, 2013) that research serves to aid policy development by allowing policy-makers to make sense of the social world and to anticipate the likely reaction of social-actors to policy initiatives. In this sense then, evidence rather than detail any objective reality, merely illuminates the range of perspectives that exist in relation to (or behaviours that might occur as a result of) given policy areas/programmes. The potential optimality of a given policy will thus be enhanced as salient perspectives are engaged with. Conversely, refusing to engage with alternative perspectives simply on the basis of dogma or partisanship serves to act as a boundary to the optimality of policies: the smaller the agora the more likely its optimality will be constrained.

In part, limiting the enactment of evidence misuse depends upon an effective differentiation between the roles of politicians and Civil Servants in the policy process and correspondingly, a re-specification of their respective domains. For example, the effects of evidence misuse will be particularly pronounced in areas such as education where these roles have become 'overlapped'. In other words, in areas where politicians, rather than simply specify the outcomes they require, also specify the inputs; the particular policies and programmes that might serve to achieve these outputs. This occurs when, for instance, politicians specify particular modes of pedagogy (for instance teaching via specific types of phonics) or the exact subjects that should form part of the curriculum (as opposed to stating that reading and writing skills need to be improved or that children should receive a broader curriculum or one which works to reduce the instances of them developing extremist attitudes etc.). One example of this type of prescription is the Secretary of State for Education, Michael Gove's attempted reform of the national curriculum in England and Wales. In June 2012, The 
Guardian newspaper announced that Gove's proposals had been decried as "fatally flawed" by Professor Andrew Pollard, a member of the expert panel involved in advising on the changes. ${ }^{3}$ The reasons for this, it would seem, include Pollard's view that Gove and Schools Minister Nick Gibb, had already decided upon a desired course of action. Pollard argues in his blog, ${ }^{4}$ for example, that "the voice that has really counted from beginning to the end has been that of an American educator, Ed Hirsch..." and that "When I first met Nick Gibb, Hirsch's Core Knowledge Sequence was open on his desk, heavily stickered with Post-It notes". Subsequently Professor Pollard suggests that: "it is Hirsch's very detailed year-onyear model that has prevailed. This was one of the main issues which caused the Expert Panel as a whole to withdraw from the development of programmes of study, leaving only Tim Oates [the head of the review team] to work with Ministers". In other words, that Ministers had decided on a specific course of action and on detailed changes that they had wished to make, leaving very little scope for expert advisors, or others, to suggest alternatives.

That this might comprise evidence misuse is highlighted in the Guardian's article when it is noted by Christine Blower, general secretary of the National Union of Teachers, that: "It is extraordinary that the secretary of state would establish an expert panel to look into the national curriculum and then choose to ignore their advice. This government seems determined to impose its vision of education regardless of the evidence or professional opinion." Likewise, comments by Stephen Twigg (Labour's current shadow education secretary), also point to Gove's proposals constituting a misuse of evidence: "It now seems that after commissioning an in-depth review, the government is ignoring many of its recommendations in favour of its own prejudice. [The government] should put evidence ahead of dogma when it comes to education. The curriculum mustn't be prey to political ideology."

\section{Conclusion}

Over the course of this paper, I have examined extant notions of power, presented a definition of evidence misuse and illustrated its negative consequences. In particular, I have

\footnotetext{
${ }^{3}$ The full article may be accessed via: http://www.guardian.co.uk/education/2012/jun/12/michaelgove-curriculum-attacked-adviser

${ }^{4}$ The blog entry may be accessed via: http://ioelondonblog.wordpress.com/2012/06/12/proposedprimary-curriculum-what-about-the-pupils/
} 
juxtaposed the ways in which Habermas and Foucault tackle notions of power: arguing that whilst both focus on how civic society does or might function, they employ fundamentally opposing approaches. In doing so I have highlighted the tension between the ideal of evidence-informed policy, where decisions are made in keeping with the 'force of the better argument' and the often experienced reality, where discourse serves to influence what this better argument might be. Combining this analysis with my data, I have set out the notion of the policy agora, a concept grounded firmly in Foucaultian notions of discursive control and 'regimes of truth' and have illustrated how a narrowly defined policy agora will serve to prevent the development of policy that is perhaps 'truly' effective, efficient and equitable in nature (with the resultant notion of evidence misue applying to actions which seek, because of dogmatic concerns, to narrow the agora at the cost of optimality).

I have also suggested, however, that in a democratic society it is both unfeasible and undesirable to employ a fully technocratic approach to policy development. The process of policy making requires more than an ability to read evidence, judge its quality and then enact its findings; policy-makers whether politicians or Civil Servants must employ both values and a wealth of skills when deciding what is right for the education of a nation. This leads me to conclude that evidence misuse, while detrimental to the optimality of policy development cannot and should not be totally eliminated from the policy process. At the same time, however, it is exactly because policy development based on dogmatic ideological adherence, is unlikely to result in truly effective solutions that instances of evidence misuse should be kept to an appropriate level. To do so requires balance; the establishment of an appropriate mix between the development by politicians of ideological, strategic, choices on educational outcomes (which should be considered an integral part of the democratic process) and the employment of evidence to help inform the most effective ways to meet these outcomes by Civil Servants. 


\section{References}

Argyris, C and Schön, D. (1974) Theory in Practice: Increasing Professional Effectiveness, (San Francisco, Jossey-Bass).

Atkinson, E. (2000) In defence of ideas, or why 'what works' is not enough, British Journal of Sociology of Educational, 21, 3, pp. 317-30.

Ball, S. (2008) The education debate, (Bristol, The Policy Press).

Ball, S. (2012) Global Education Inc. New Policy Networks and the Neo-Liberal Imaginary (Abingdon, Routledge).

Brown, C. (2011) What factors affect the adoption of research within educational policy making? How might a better understanding of these factors improve research adoption and aid the development of policy? Unpublished DPhil Dissertation, University of Sussex.

Brown, C. (2011a) Exploring the concepts of knowledge adoption and conceptual impact: implications for educational research submissions to the Research Excellence Framework (2014), Evidence, Knowledge and Economy Journal, 5, 3, pp. 137-154 .

Brown C. (2013) Making evidence matter: new perspectives on evidence-informed policy making in education, (London, IOE Press).

Brown, A., and Dowling, P. (1998) Doing Research/Reading Research: A mode of interrogation for education, (London, Falmer Press).

Chomsky, N. and Foucault, M. (1974) Human Nature: Justice versus Power, in: Elders, F. (Ed) Reflexive Water: The Basic Concerns of Mankind, (London, Souvenir Press).

Eurydice Network (2012) Entrepreneurship Education in Schools in Europe, available at, http://eacea.ec.europa.eu/education/eurydice/documents/thematic_reports/135EN.pdf, accessed 26 May 2012. 
Flyvbjerg, B. (1998), Habermas and Foucault: Thinkers for Civil Society?, British Journal of Sociology, 49,2, pp208-233.

Flyvbjerg, B. (2001), Making Social Science Matter: Why Social Inquiry Fails and How It Can Succeed Again (Cambridge, Cambridge University Press).

Foucault, M. (1978) The History of Sexuality, Vol 1: An introduction, (Harmondsworth, Penguin).

Foucault, M. (1980) Power/Knowledge: Selected Interviews and Other Writings, 1972-1977, (New York: Pantheon).

Foucault, M. (2004) Society must be defended, (London, Penguin)

Gibbons, M. (1999) Science's new social contract with society, Nature, 404, pp. C81-C84.

Gibbons, M., Limoges, C., Nowotny, H., Schwartzman, S., Scott, P. and Trow, M. (1994) The New Production of Knowledge: The Dynamics of Science and Research in Contemporary Societies, (London, Sage).

Habermas, J.(1990) Moral Consciousness and Communicative Action, (Cambridge, MA, MIT Press).

Habermas, J. and Cooke, M. (Ed)(1999) On the Pragmatics of Communication, (Cambridge, MA, MIT Press).

Habermas, J. (undated) On the relationship of Politics, Law and Morality (Frankfurt, University of Frankfurt).

Hargreaves, A. and Harris, A. (2011) Performance beyond expectations (Nottingham, National College for School Leadership).

Innes, J. (1995). Planning Theory's Emerging Paradigm: Communicative Action and Interactive Practice, Journal of Planning Education and Research, 14,3, pp.183-190. 
Lauria, M \& Soll, M. (1996) Communicative Action, Power, and Misinformation in a Site Selection Process, Journal of Planning Education and Research, 15,3, pp.199-211.

Lukes, S. (2005) Power: A Radical View (2 ${ }^{\text {nd }}$ edition) (Basingstoke, Palgrave Macmillan).

Mountfield, R. (1999) "Politicisation" and the civil service, available at: www.civilservant.org.uk/politicisation.pdf, accessed 5 September 2012

Nowotny, H., Scott, P. and Gibbons, M. (2003) 'Mode 2' Revisited: The New production of Knowledge, Minerva, 41, pp. 179-194.

Oakley, A. (2000) Experiments in knowing: gender and method in the social sciences, (Cambridge, Polity Press).

Ouimet, M., Landry, R., Ziam, S., Bedard, P-O. (2009) The absorption of research knowledge by public Civil Servants, Evidence and Policy: A Journal of Research, Debate and Practice, 5, 4, pp. 331-350.

Oxman, A., Lavis, J., Lewin, S., and Fretheim, A. (2009) SUPPORT Tools for evidence-informed health Policymaking (STP) 1: What is evidence-informed policymaking?, available at: http://www.health-policy-systems.com/content/7/S1/S1, accessed on 14 November 2010.

Rickinson, M., Sebba, J. and Edwards, A. (2011) Improving research through user engagement, (London: Routledge).

Schön, D. (1983). The Reflective Practitioner, (New York, Basic Books).

Shore, C., and Wright, S. (1999) Audit Culture and anthropology: neo liberalism in British higher education, The Journal of the Royal Anthropological Institute, 5, pp. 557-575.

Sylva, K., Taggart, B., Melhuish, E., Sammons, P. and Siraj-Blatchford, I. (2007) Changing models of research to inform educational policy, Research papers in Education, 22, 2, pp. 155-168. 
Taggart, B., Siraj-Blatchford, I., Sylva, K., Melhuish, E. and Sammons, P. (2008) Influencing Policy and Practice through Research on Early Childhood Education, International Journal of Early Childhood Education, 14, 2, pp. 7-21.

Trowler, P. (2003) Education Policy, (London, Routledge). 